\title{
Providing interlayer adhesion of dissimilar layers of top road surfaces
}

\author{
Talgat Gabdullin*1[0000-0001-8232-4225], and Marat Makhmutov ${ }^{1}$ \\ ${ }^{1}$ Kazan State University of Architecture and Engineering, 420043 Kazan, Russia
}

\begin{abstract}
The article reviews the option of how to make the top pavement of asphalt-concrete mixture adhere reliably to the base, which is the underlying cement-concrete coating. The bitumen-latex emulsion is suggested as a binder for the two pavement layers. The research aimed to determine the optimal layer thickness of the bituminous-latex emulsion to be applied and achieve the maximum interlayer adhesion between the top asphalt-concrete pavement and the cement-concrete base. After full-scale experiments, the required layer thickness of the bitumen-latex emulsion was $2 \mathrm{~mm}$. With this layer thickness of the binder, road pavement layers do not delaminate and shear when stressed by the intensive flows of vehicles moving on the roads. The results obtained are important for the road construction industry for suggesting the formulation of bitumen-latex emulsion and finding the most effective layer thickness to be applied. The suggested formulation of a bitumen-latex emulsion is frost-resistant. The article describes the experimental steps for determining the optimal application thickness at a fair length. The maintenance-free life of roads with an asphalt-concrete mixture on a cement-concrete base interlayered with a bitumen-latex emulsion as a binder is assumed to get much longer.
\end{abstract}

Keywords. Road surface, asphalt concrete mixture, cement concrete mixture, composition, bitumen-latex emulsion, thickness, load, method.

\section{Introduction}

The topic of highways has always been a problem for our state. Therefore, the correct selection of materials for road construction will ensure the durability and reliability of the road structure. And good roads are an indicator of the economic stability of the state and the quality of life of its citizens.

In Russia, the adhesion of asphalt concrete layers is determined in accordance with paragraph 12.5.2 of the Joint Venture. In accordance with, the quality control of the adhesion of asphalt concrete coating layers is provided, while the control method, as well as numerical indicators, is not specified. It can be assumed that this is a visual inspection of the solidity of the core extracted by the core collector without determining the numerical value of the adhesion force. Using this method, it is possible to visually state the lack of traction, but in the presence of traction, it is impossible to assess its quality.

${ }^{*}$ Corresponding author: Talgat2204@mail.ru 
When using asphalt concrete, the determining role is played by the shear resistance of the coating, especially in the case of its reinforcement. Therefore, in Europe, when using geosynthetic materials in the coating layers, one of the main ones is the cut test of the asphalt concrete core on the reinforcing material. In Russia today, there are no regulatory documents regulating this laboratory test. Based on this, in case of extreme necessity, reference is made to the method of determining the coupling used in Germany, which shows the amount of shear resistance. But, as practice has shown, laboratories are not equipped with this equipment and do not own this technique. In accordance with the German standard DIN1996 T7 [8], the adhesion of asphalt concrete coating layers is determined by the amount of resistance to shear of a core with a diameter of $0.15 \mathrm{~m}$, the numerical value of which must be at least $15 \mathrm{kN}$.

The requirements for the shear resistance of asphalt concrete core are also set out in the regulatory document FGSVNr 69 [9]. In the case of a change in the diameter of the test core, the requirement for the minimum value of the sample's shear resistance is correlated taking into account the proportionality of the value to the square of the core diameter [10]. The experience of road workers has shown that the problem of the impossibility of numerical evaluation of the adhesion between the layers of coatings as non-rigid-non-rigid, and nonrigid-rigid is massive, and the lack of a regulatory framework significantly exacerbates it.

The motor vehicle fleet grows steadily country-wide, as does their carrying capacity, cargo sizes, and traffic intensity and speed. As a result, there is a greater demand for betterfunctioning roads [1-4].

Many Russian and foreign scientists are researching ways to improve road quality and lengthen their maintenance-free life. In their articles [5-8], the authors suggested various methods for self-recovery of road materials as a means of addressing pavement durability and stability issues. Other researchers suggested that improving the compaction of top road surfaces could fix this issue [9-12]. Article [13] suggests using reinforcement and cementconcrete slabs to protect damaged asphalt pavements better. In [14-17], the authors recommend that pavement materials be improved, as well as the methods for removing wheel ruts from roads. In [18-21], the researchers studied the behavior and assessment of the state of asphalt-concrete mixture pavements when traffic loads occur. The authors' studies aimed at improving bitumen and the compounds it creates with road-building materials are of real practical value [22-25]. The authors' research [26-28] yielded recommendations on improving the quality of road pavements by reducing climatic effects on the pavement in a variety of ways. The articles [29-33] describe and study how to solve the issues of increasing the durability of top road surfaces by improving the quality of roadbed erection.

The experience gained in Russia and abroad (USA, China, Germany, etc.) also testifies that the growing demands for road traffic nowadays are better satisfied by rigid road surfaces like cement concrete.

So, the most potent way to improve the physical state of the Russian motor road network is to build roads with the top cement-concrete pavements overlaid with layers of the asphaltconcrete mixture.

The purpose of the research is to determine the optimal thickness of the bituminous-latex emulsion application, which ensures maximum interlayer adhesion of the upper asphalt concrete coating with the cement concrete base.

\section{Materials and methods}

The optimal layer thickness of bitumen-latex emulsion as a binding compound between the two top layers of the road surface was found by experiments; the samples of the two-layer top road pavement bound together with bitumen-latex emulsion were tested in situ. 


\subsection{Preparation of experiment}

A bitumen-latex emulsion with the composition shown in table 1 was developed for the experiment.

Table 1. The composition of the bitumen-latex emulsion.

\begin{tabular}{|l|c|}
\hline \multicolumn{1}{|c|}{ Component } & Content, $\%$ \\
\hline Polyacrylamide & $1.0 \%$ \\
\hline STARLATEX & $3.0 \%$ \\
\hline Emulsifier & $0.6 \%$ \\
\hline HCL & $0.25 \%$ \\
\hline Water & $46.0 \%$ \\
\hline BND 90/130 bitumen & $49.0 \%$ \\
\hline
\end{tabular}

The bitumen emulsion is a liquid bitumen that has been emulsified by combining it with an emulsifier aqueous solution [21-23]. The mixture is homogeneous, it has the texture of milk and good adhesive properties. Brown is the base color, with different shades varying from light to dark. The low viscosity of emulsions allows stone materials to be worked with no heat-up. Furthermore, the emissions of hazardous compounds into the atmosphere are much lower than those of hot bitumen. GOST R 52128-2003 (Russian Standard) regulates the properties of emulsified bitumen.

In general, bituminous emulsions are used in construction, which includes:

1. Bitumen, $30-70 \%$ of the total mass. The most popular mixtures contain $50-55 \%$ bitumen. Oil road bitumen grades BND 90/130, BND 130/200 are commonly used when preparing emulsions. A polymer-bitumen binder has better performance properties compared to ordinary bitumen and is used to produce a high-quality mixture.

2. Water. The mass fraction is $15-70 \%$.

3. Emulsifier (0.15-3\%). Emulsifiers are surfactants that are dissolved in all phases (water and binder) or one of them. They can be anionic or cationic. In rare cases, fine mineral powders such as cement, clays, soot, carbonates, or oxides can replace surfactants.

4. Stabilizer. The mass fraction is $0.05-0.5 \%$. Used only in emulsions with cationic surfactants. An aqueous solution of calcium chloride or other water-soluble salts, as well as acids (orthophosphoric, hydrochloric, acetic), can be used to reach this purpose.

5. Some additional components. These can be solvents, polymers, dilutes, or modifying additives. Modified bitumen emulsion is produced when using modified or ordinary bitumen. Latex, epoxy, polyethylene, synthetic resin, or rubber are added to the ordinary bitumen-based product.

The particles in the mixture are usually no larger than 1.5 microns in size.

The temperature of the bitumen emulsion when it is poured varies according to the ambient temperature range. At temperatures higher than $+20^{\circ} \mathrm{C}$ the composition is not heated. At temperatures below $+20^{\circ} \mathrm{C}$, it must be pre-heated to $+40-+70^{\circ} \mathrm{C}$ before pouring. The material should preferably be stored at a temperature above $0^{\circ} \mathrm{C}$.

Properties of the bitumen emulsion giving it an advantage over ordinary bitumen:

- low viscosity, so the material penetrates even into the smallest pores of a base layer:

- adheres very well to the base;

- road construction works are possible when relative air humidity is high and temperatures are low;

- the material is dosed very accurately and distributed as a thin layer across the base;

- energy carrier savings for pre-heating before using the material.

- environmental compliance and no harm to human health due to the minimal amount of harmful emissions going into the atmosphere. GOST 12.1.007 classifies the emulsion as a low-hazard substance, and its effect on the human body is the 4th class of hazard;

- high level of fire safety. 


\subsection{How to prepare samples}

First, a plastic mold was mounted on the cement concrete samples with a diameter of 71.4 $\mathrm{mm}$. Then, at $90 \ldots 100^{\circ} \mathrm{C}$, a ready-made bitumen-latex emulsion was poured into the resulting molds in varying thicknesses. After that, the plastic was removed, and asphalt concrete samples were bonded to the resulting bases (Fig. 1).

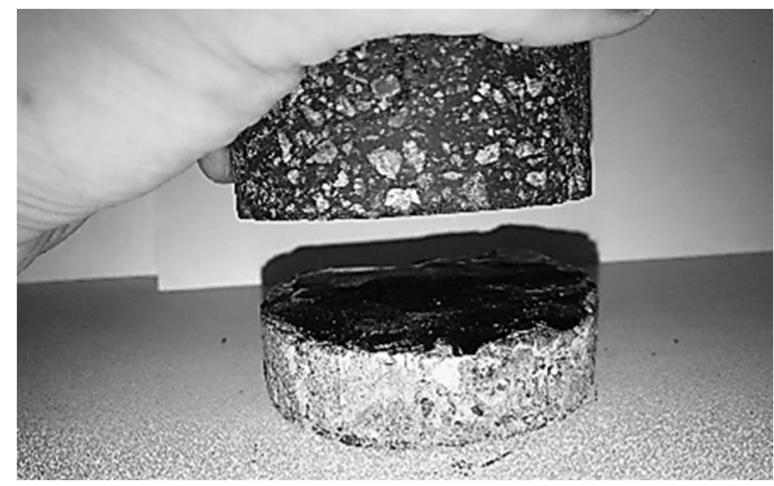

Fig. 1. How the samples are bonded (illustration by the authors).

After the samples of asphalt concrete mixture were bonded to cement concrete samples, they were further tested on the PSG-3M unit using the non-consolidated undrained shear method as per GOST 12248-10.

The thicknesses of bitumen-latex emulsion used in the experiment were: $2 \mathrm{~mm}, 3 \mathrm{~mm}, 4$ $\mathrm{mm}$, and $5 \mathrm{~mm}$ (Figures 2a-d).

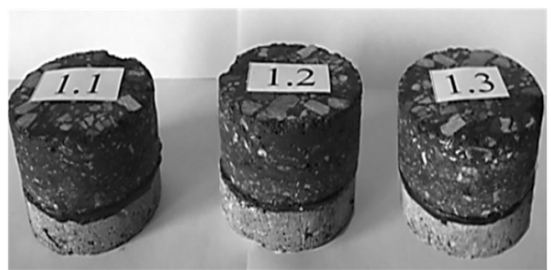

a) The bonding layer is $2 \mathrm{~mm}$ thick (illustration by the authors)
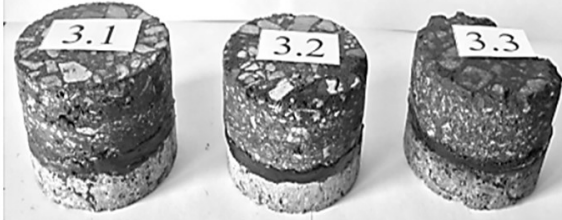

c) The bonding layer is $4 \mathrm{~mm}$ thick (illustration by the authors)

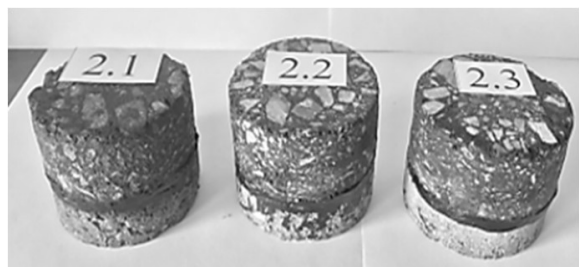

b) The bonding layer is $3 \mathrm{~mm}$ thick (illustration by the authors)

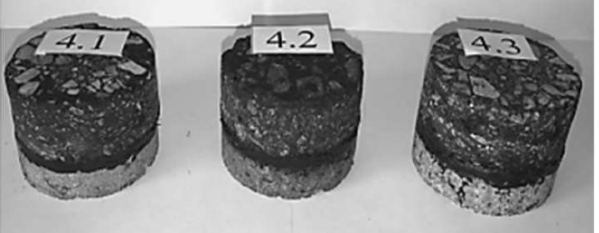

d) The bonding layer is $5 \mathrm{~mm}$ thick (illustration by the authors)

Fig. 2. Samples with the bonding layer of various thicknesses.

Each thickness had three pre-made batches of three samples each for the accuracy of the experiment. The best result from the batch was selected and used for further comparison.

The samples were tested according to GOST 12248-2010 requiring them to be tested for shear strength under various normal stresses: $0.1 \mathrm{MPa}$; $0.2 \mathrm{MPa} ; 0.3 \mathrm{MPa}$.

The normal compressive force is found by the formula [4]:

$$
\sigma=10 \frac{F}{A},
$$


where $F$ is the normal force to the shear plane, respectively, $\mathrm{kN}$;

$\sigma$ is the vertical stress, $\mathrm{MPa}$;

$A$ is the sample area, $\mathrm{m}^{2}, A=0,004 \mathrm{~m}^{2}$.

$$
F=\frac{\tau \cdot A}{10}
$$

for $\sigma=0.1 \mathrm{mPa}$ :

$$
F=\frac{0.1 \cdot 10^{6} \text { Па } \cdot 0.004 \mathrm{~m}^{2}}{10}=40 \mathrm{~N}
$$

To find the weight of the suspended load, let us use the formula:

$$
F=m \cdot g
$$

where $\mathrm{m}$ is the weight of the load, $\mathrm{kg}$,

$g$ is the acceleration of gravity, $g \approx 9.82 \frac{\mathrm{m}}{\mathrm{s}^{2}}$.

for $\sigma=0.2 \mathrm{mPa}$ :

$$
\mathrm{m}=\frac{\mathrm{F}}{\mathrm{g}}=\frac{40}{9,82} \approx 4 \mathrm{~kg}
$$

$$
\begin{gathered}
F=\frac{0,2 \cdot 10^{6} \Pi \mathrm{a} \cdot 0,004 \mathrm{~m}^{2}}{10}=80 \mathrm{~N} . \\
m=\frac{80}{9,82} \approx 8 \mathrm{~kg} .
\end{gathered}
$$

for $\sigma=0.3 \mathrm{mPa}$ :

$$
\begin{gathered}
F=\frac{0,3 \cdot 10^{6} \Pi \mathrm{a} \cdot 0,004 \mathrm{~m}^{2}}{10}=120 \mathrm{~N} . \\
m=\frac{120}{9,82} \approx 12 \mathrm{~kg} .
\end{gathered}
$$

To produce vertical stress, the weight of the mechanism, which is $0.5 \mathrm{~kg}$, was factored in. To create normal stress on the lower suspension, loads of $3.5 \mathrm{~kg}$ for $0.1 \mathrm{MPa}, 7.5 \mathrm{~kg}$ for 0.2 $\mathrm{MPa}$, and $11.5 \mathrm{~kg}$ for $0.3 \mathrm{MPa}$ are required. Thus, the total vertical stress applied to the sample is $4 \mathrm{~kg}$ at $0.1 \mathrm{MPa} ; 8 \mathrm{~kg}$ at $0.2 \mathrm{MPa}$; and $12 \mathrm{~kg}$ at $0.3 \mathrm{MPa}$ (Table 2).

Table 2. Weight of the load on the shear arm suspension vs. tangential stress.

\begin{tabular}{|c|c|c|}
\hline $\begin{array}{c}\text { Time from beginning of } \\
\text { the experiment, } t, \mathrm{~s}\end{array}$ & $\begin{array}{c}\text { Weight of the load on the shear } \\
\text { arm suspension, } M, \mathrm{~kg}\end{array}$ & Tangential shear stress, $T, \mathrm{mPa}$ \\
\hline \multicolumn{3}{|c|}{ At normal stress $\sigma-0.1 \mathrm{mPa}:$} \\
\hline 10 & 0.4 & 0.01 \\
\hline 20 & 0.8 & 0.02 \\
\hline 30 & 1.2 & 0.03 \\
\hline 40 & 1.6 & 0.04 \\
\hline 50 & 2 & 0.05 \\
\hline 60 & 2.4 & 0.02 \\
\hline \multicolumn{3}{|c|}{ At normal stress $\sigma-0.2 \mathrm{mPa}:$} \\
\hline 10 & 0.8 & 0.04 \\
\hline 20 & 1.6 & 0.06 \\
\hline 30 & 2.4 & 0.08 \\
\hline 40 & 3.2 & 0.1 \\
\hline 50 & 4 & 0.12 \\
\hline 60 & 4.8 & 0.03 \\
\hline \multicolumn{3}{|c|}{ At normal stress $\sigma-0.3 \mathrm{mPa}:$} \\
\hline 20 & 1.2 & 0.06 \\
\hline 30 & 2.4 & 0.09 \\
\hline 40 & 3.6 & 0.12 \\
\hline 50 & 4.8 & 0.18 \\
\hline 60 & 6 & \\
\hline
\end{tabular}


Using the method of GOST 12248-2010, a load of $10 \%$ of the vertical stress was applied stepwise when the horizontal shear stress was produced. This experiment could only be considered finished when the shearing strain was over $5 \mathrm{~mm}$.

When the samples were tested, a load of $3.5 \mathrm{~kg}$ was suspended on the mechanism for producing vertical stress of $0.1 \mathrm{MPa}$. Next, right after the normal stress was transferred, the horizontal stress-producing mechanism was actuated by placing a $0.4 \mathrm{~kg}$ load on the suspension. Then, the load on the horizontal shear load suspension was stepped up $10 \%$ from the normal stress every 10 seconds. The test was considered finished if the shear strain was over $5 \mathrm{~mm}$.

For tests at $\sigma=0.2 \mathrm{MPa}$, the load on the suspension was $7.5 \mathrm{~kg}$ to produce vertical stress and $0.8 \mathrm{~kg}$ to produce horizontal stress.

For tests at $\sigma=0.3 \mathrm{MPa}$, the weight of the load on the suspension was $11.5 \mathrm{~kg}$ to produce vertical stress and $1.2 \mathrm{~kg}$ to produce horizontal stress.

For each test sample with different layer thicknesses of bitumen-latex emulsion, we plotted the shear strength vs. normal stress and the shear strain vs. tangential stress.

\section{Results}

Test results for the bitumen-latex emulsion $2 \mathrm{~mm}$ thick

At normal stress of $\sigma=0.1 \mathrm{MPa}$, the shear strain of more than $5 \mathrm{~mm}$ reached $\tau=0.06$ $\mathrm{MPa}$ at horizontal shear stress and the loads on the suspension were $2.4 \mathrm{~kg}$. $A_{t} \sigma=0.2 \mathrm{MPa}$, $\tau=0.12 \mathrm{MPa}$, the loads on the suspension were $4.8 \mathrm{~kg}$, and at $\sigma=0.3 \mathrm{MPa}, \tau=0.18 \mathrm{MPa}$, the loads on the suspension were $7.2 \mathrm{~kg}$ (Figures 3-5).

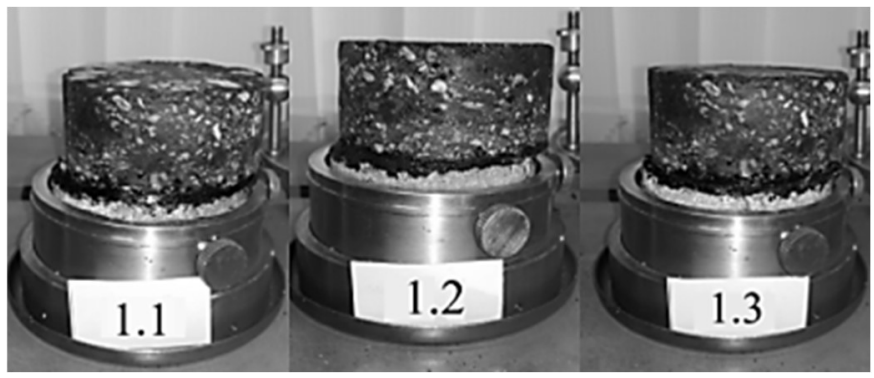

Fig. 3. Test results for the bitumen-latex emulsion $2 \mathrm{~mm}$ thick.

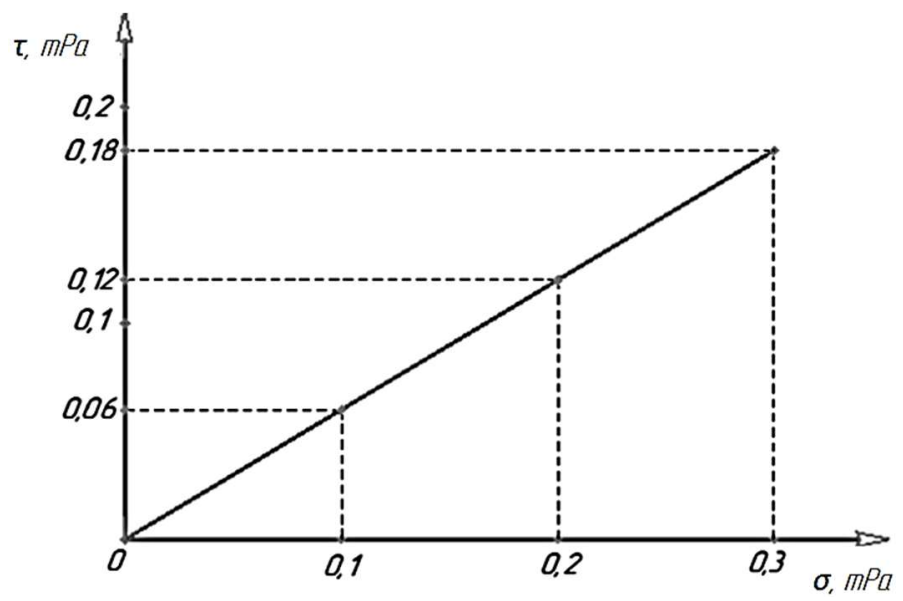

Fig. 4. Shear strength vs. normal stress graph $\tau=f(\sigma)$ for the bonding emulsion layer $2 \mathrm{~mm}$ thick. 


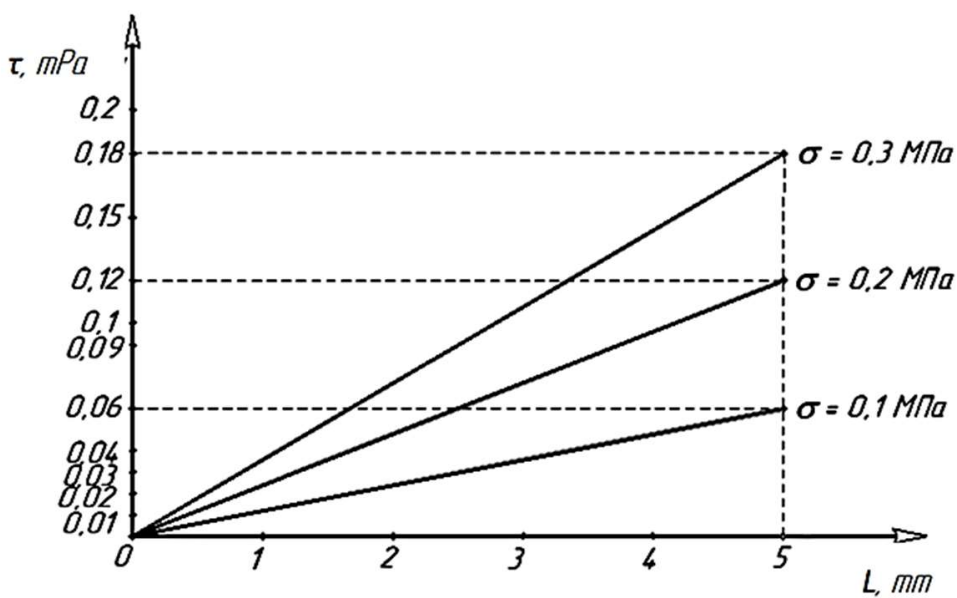

Fig. 5. Shear strain vs. tangential stress graph, $l=f(\tau)$ for the bonding emulsion layer $2 \mathrm{~mm}$ thick).

The next tests were carried out according to the same methodology as for the bitumenlatex emulsion layer $2 \mathrm{~mm}$ thick.

The test data for the bitumen-latex emulsion layers 3,4 , and $5 \mathrm{~mm}$ thick is summarized in table 3 .

Table 3. The experiment data for achieving a shear strain of over $5 \mathrm{~mm}$.

\begin{tabular}{|c|c|c|}
\hline \multicolumn{4}{|c|}{ Thickness of bitumen-latex emulsion $\mathbf{2 ~} \mathbf{~ m m}$} \\
\hline Normal stress, $\sigma, \mathrm{mPa}$ & Horizontal shear stress $\tau, \mathrm{mPa}$ & Weight of suspended loads $m, \mathrm{~kg}$ \\
\hline 0.1 & 0.06 & 2.4 \\
\hline 0.2 & 0.12 & 4.8 \\
\hline 0.3 & 0.18 & 7.2 \\
\hline \multicolumn{3}{|c|}{ Thickness of bitumen-latex emulsion $\mathbf{3} \mathbf{~ m m}$} \\
\hline 0.1 & 0.05 & 2.0 \\
\hline 0.2 & 0.1 & 4.0 \\
\hline 0.3 & 0.15 & 6.0 \\
\hline \multicolumn{3}{|c|}{ Thickness of bitumen-latex emulsion $\mathbf{4} \mathbf{~ m m}$} \\
\hline 0.1 & 0.03 & 1.2 \\
\hline 0.2 & 0.06 & 2.4 \\
\hline 0.3 & 0.09 & 3.6 \\
\hline \multicolumn{3}{|c|}{ Thickness of bitumen-latex emulsion $\mathbf{5} \mathbf{~ m m}$} \\
\hline 0.1 & 0.02 & 0.8 \\
\hline 0.2 & 0.04 & 2.6 \\
\hline 0.3 & 0.06 & 2.4 \\
\hline
\end{tabular}

\section{Discussions}

The key goal of the experiment was to determine the optimal thickness of the bituminouslatex emulsion layer on the cement-concrete base, followed by placing a top («finishing») layer of the asphalt-concrete mixture on the concrete.

The tests found that the bitumen-latex emulsion layer on the cement concrete base provides the best shear resistance and hence the best interlayer binder when applied at the thickness of $2 \mathrm{~mm}$.

In the course of the experiment, the bitumen-latex emulsion layers thicker than $5 \mathrm{~mm}$ and thinner than $2 \mathrm{~mm}$ between samples of the asphalt-concrete mixture and cement-concrete samples were not addressed. It is not rational to use a layer thicker than $5 \mathrm{~mm}$ for laying, as 
there will be a loss of shear strength under normal stress. Using a layer thinner than $2 \mathrm{~mm}$ is technologically challenging in terms of keeping the bonding layer even and accurate when it comes to producing it.

When installing reinforcement layers on prefabricated surfaces, in addition to the main load-bearing layers of dense asphalt concrete, a leveling layer of fine-grained or porous asphalt concrete, less often of black crushed stone, is laid. These layers also serve as a crackbreaking layer. As a result, the total thickness of the non-rigid part of the coating is at least $0.15 \mathrm{~m}$, which makes it irrelevant that the reinforcement layer adheres to the plate coating. At the same time, the lack of adhesion between the rigid and non-rigid layers makes it possible to reduce (or eliminate for the estimated period of time in the case of geotextile materials) the negative impact of horizontal movements of the prefabricated coating during seasonal temperature differences that affect the size of crack opening and the speed of their exit to the surface of the asphalt layer. The main attention should be paid to the amount of adhesion of asphalt concrete layers to each other, especially when installing airfield coverings. The minimum thickness of the structural top layer of asphalt concrete should be at least $0.05 \mathrm{~m}$ [12], then, accordingly, the application of a tear-off load of $12 \mathrm{kPa}$ is sufficient for the destruction of the structure [11]. The adhesion of asphalt-concrete reinforcement layers is achieved by the technology of laying the upper layers without cooling the mixtures of the lower layer, by the influx of bituminous emulsion.

\section{Conclusion}

The research findings give rise to the following suggestions:

1. The bitumen-latex emulsion as a binding layer between the cement concrete base and the top layer of the asphalt-concrete mixture road is suggested.

2. The optimal thickness of the binding bitumen-latex emulsion layer of $2 \mathrm{~mm}$ was found through experiments to give the top road pavement the best shear strength.

3. With this layer thickness of the binder, road pavement layers do not delaminate and shear when stressed by the intensive flows of vehicles moving on the roads.

4. The use of bitumen-latex emulsion in the construction of roads paved with dissimilar top layers is a powerful and low-cost way of achieving inter-layer bonding in the top layers of road pavement.

5. This reduces shear destructions in the top pavement of the asphalt concrete mixture. These destructions are known to shorten the recommended inter-repair intervals and compromise road traffic safety.

\section{References}

1. G.P. Ivanov, I.V. Grishin. On the problem of road construction-the presence of cracks in the asphalt concrete coatings of roads and bridges and ways to solve them, Scientific Internet Journal 11, 1-8 (2019).

2. A.G. Ismagilov, R.N. Zolin, R.L. Sakhapov, M.M. Makhmutov. Improving the technical and operational characteristics of the road surface, Transport engineering and technology 1 (2), 1-3 (2017).

3. T.R. Gabdullin. New technologies of road construction in Russia, Materials of the international scientific and practical conference «Innovative materials, technologies and equipment for the construction of modern transport structures», publishing House of BSTU named after V.G. Shukhov, Belgorod, 109-113 (2013).

4. V.P. Podolsky. Technology and organization of the construction of roads, Road coverings, 304 (2012). 
5. SP 78.13330.2012. Svod pravil. Avtomobil'nye dorogi. Aktualizirovannaya redakciya SNiP 3.06.03-85. Utverzhden Prikazom Ministerstva regional'nogo razvitiya Rossijskoj Federacii (Minregion Rossii) ot 30 iyunya 2012 g. № 272 i vveden v dejstvie s 1 iyulya 2013, g. 53 s.

6. S. Inozemtcev, E. Korolev. Active polymeric reducing agent for self-healing asphalt concrete, IOP Conf. Series: Materials Science and Engineering 1030, 012002 (2021). DOI: $10.1088 / 1757-899 X / 1030 / 1 / 012002$.

7. S.S. Inozemtcev, E.V. Korolev. Review of Road Materials Self-healing: Problems and Perspective, IOP Conference Series: Materials Science and Engineering 855 (1), 012010 (2020).

8. DIN 1996 Teil 7. Priifung von Asphalt. Bestimmung von Rohdichte, Raumdichte, Hohiraumgehalt und Verdichtungsgrad. - Berlin: DIN Deut-schesInstitut fur Normung e. V. 1992.10 p.

9. Verwendung von Vliesstoffen. Gittem und Verbundstof - fen im Asphaltstrafienbau. FGSV Arbeitspapier Nr., 14 (2010).

10. N.V. Bystrov, G.A. Generalov. Ocenka effektivnosti geosinteticheskih materialov pri remonte asfal'tobetonny pokrytij, Dorkomstroj 1, 14-16 (2005).

11. V.E. Trigoni, T.P. Leshchickaya, A.I. Yurchenko. Povyshenie dolgovechnosti asfal'tobetonnyh sloev usileniya pri rekonstrukcii aerodromov. M. 1998.

12. SP 121.13330-2012 «SNiP 32-03-96 «Aerodromy», Minregion Rossii, M. 2012.98 p.

13. E. Schlangen, S. Sangadji. Addressing infrastructure durability and sustainability by self-healing mechanisms - Recent advances in self-healing concrete and asphalt, Procedia Engineering 54, 39-57 (2013).

14. Bin Xue, Huifeng Wang, Jianzhong Pei, Rui Li, Jiupeng Zhang. Zepeng Fan Study on selfhealing microcapsule containing rejuvenator for asphalt, Construction and Building Materials 135, 641-649 (2007).

15. Ammann compaction expert. Intelligent compaction, Ammann America Inc., 16 (2006).

16. Basic principles of asphalt compaction, Bomag GmbH. - Hellerwald, 59 (2009).

17. Q. Xu et al. Hot mix asphalt intelligent compaction - a case study, Transportation research board $89^{\text {th }}$ annual meeting 10 (2213), 17 (2010).

18. G.W. Maupin Jr. Preliminary field investigation of intelligent compaction of hotmix asphalt, Virginia Transportation Research Council VTRC 08-R7, 18 (2007).

19. P. Radziszewski, W. Jackiewicz-Rek, M. Sarnowski, M. Urbański. Fortification of Damaged Asphalt Pavements with Cement Concrete Slabs Reinforced with Next-Gen Bars - Part I, Laboratory StudyArchives of Civil Engineering 64 (3), 67-80 (2018).

20. Blazejowski Krzystof, Stanislaw Styk. Technologia warstw asfaltowych. - Warszawa: Widawnictwa Komunikacji i lacznosci, 406 (2004).

21. G. Garcia, M. Thompson. Considerations for Extended-Life Hot-Mix Asphalt Pavement Design, Transportation Research Record: Journal of the Transportation Research Board, 3-11 (2008).

22. M.A. Ahammed, S.L. Tighe. Pavement surface mixture, texture and skid resistance: A factorial analysis Airfield and Highway Pavements: Efficient Pavements Supporting Transportation's Future, Proceedings of the 2008 Airfield and Highway Pavements Conference 329, 370-384 (2008).

23. J. Button, D. Perdomo, R. Lytton. Influence of aggregate on rutting in asphalt concrete pavements, Transportation Research Record 1259, Transportation Research Board, Washington, D.C., 19-31 (1990).

24. Prithvi S. Kandhal, Allen L. Cooley. Accelerated Laboratory Rutting Tests: Evaluation of the Asphalt Pavement Analyzer, NCHRP Report 508, (2003).

25. J.M. Krishnan, K.R. Rajagopal. On the mechanical behavior of asphalt, Mechanics of materials 37 11, 1085-1100 (2005). 
26. A.H. De Bondt. Anti-Reflective Cracking Design of (Reinforced) Asphalt Overlays, Delft: Delft University of Techno-logy, 411 (2009).

27. R.F. Hunter. Asphalt in road construction. London, United Kingdom, ICE Publishing, 588, (2014).

28. Yetkin Yildirim. Polymer modified asphalt binders. Construction and Building Materials 21, Iss. 1, January 2007, 66-72 (2007). DOI: 10.1016/j.conbuildmat. 2015.07.007.

29. Mithil Mazumder Hyunh wan Kim Soon, Jae Lee. Performance properties of polymer modified asphalt binders containing wax additives, International Journal of Pavement Research and Technology 9, Iss. 2, March 2016, 128-139 (2016). DOI: 10.1016/j.ijprt.

30. Jiqing Zhu, Björn Birgisson, Niki Kringos. Polymer modification of bitumen: Advances and challenges, European Polymer Journal 54, May 2014, 18-38 (2014). DOI: 10.1016/j.eurpolymj.

31. Davide Lo Presti Recycled Tyre Rubber. Modified Bitumens for road asphalt mixtures: A literature review, Construction and Building Materials 49, December 2015, 863-881 (2015). DOI: 10.1016/j.conbuildmat.

32. E.A. Vdovin, V.F. Stroganov. Modification of cement-bound mixtures with sodium formate additives for the construction of pavement bases at low air temperatures, IOP Conference Series: Materials Science and Engi. 065, 91-99 (2019). DOI: 10.31659/0585-430X-2016-738-6-47-49.

33. Canestrari F., Cardone F., Graziani A., Santagata F., Bahia H.U. Adhesive and Cohesive Properties of Asphalt-Aggregate Systems Subjected to Moisture Damage, Road Materials and Pavement Design 11, 11-32 (2015). DOI: 10.1080/14680629. 2010.9690325.

34. B.B. Teltayev, C.O. Rossi, G.G. Izmailova, E.D. Amirbayev. Effect offreeze-thaw cycles on mechanical characteristics of bitumens and stone mastic asphalts, Applied Sciences 9 (3), 458 (2019). DOI: 10.3390/app9030458.

35. DIN 1996 Teil 7. Priifung von Asphalt. Bestimmung von Rohdichte, Raumdichte, Hohiraumgehalt und Verdichtungsgrad. - Berlin: DIN Deut-schesInstitut fur Normung e. V. 10 p. (1992)

36. M. Oda. Initial fabrics and their relations to mechanical properties of granularmaterials, Soils Foundation 12 (1), 17-36 (1972).

37. Verwendung von Vliesstoffen, Gittem und Verbundstof - fen im Asphaltstrafienbau. FGSVArbeitspapierNr, 14 (2010).

38. M.M. Makhmutov, R.V. Nikolaeva, M.H. Gatiatullin. Asphalt granulate coating for roadsides, MATEC Web of Conferences 245, 02003 (2018). DOI: 10.1051/matecconf/ 201824502003.

39. L. Mavliev, P. Bulanov, E. Vdovin, V. Zaharov, A. Gimazov. Road soil cement with complex additives based on organosilicon compounds and electrolytes 69, 49-54 (2016). DOI: $10.1088 / 1757-899 \mathrm{X} / 327 / 3 / 032014$. 